\title{
Ambiances
}

anbiances Environnement sensible, architecture et espace urbain

\author{
$1 \mid 2015$ \\ Experiential Simulation
}

\section{Soundwalking in virtual urban ambiances. Applying Game Engine Technologies in soundscape study}

Parcours sonores dans les ambiances urbaines virtuelles. Application des technologies du moteur de jeux dans l'étude du paysage sonore

\section{Valerio Signorelli}

\section{OpenEdition}

\section{Journals}

\section{Electronic version}

URL: http://journals.openedition.org/ambiances/657

DOI: 10.4000/ambiances.657

ISSN: 2266-839X

\section{Publisher:}

Direction Générale des Patrimoines - DAPA - MCC, UMR 1563 - Ambiances Architectures Urbanités (AAU)

\section{Electronic reference}

Valerio Signorelli, «Soundwalking in virtual urban ambiances. Applying Game Engine Technologies in soundscape study », Ambiances [Online], 1 | 2015, Online since 14 September 2015, connection on 19 April 2019. URL : http://journals.openedition.org/ambiances/657 ; DOI : 10.4000/ambiances.657

This text was automatically generated on 19 April 2019

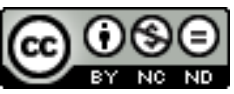

Ambiances is licensed under a Creative Commons Attribution-NonCommercial-NoDerivatives 4.0 International License. 


\title{
Soundwalking in virtual urban ambiances. Applying Game Engine Technologies in soundscape study
}

\author{
Parcours sonores dans les ambiances urbaines virtuelles. Application des \\ technologies du moteur de jeux dans l'étude du paysage sonore
}

Valerio Signorelli

\section{Introduction}

Aim of the research is to test the potentialities and limits of different technologies able to describe, in a multimodal and interactive manner, the sensory peculiarities of the urban environment. Specifically the objective is to identify operational tools able to extend the toolbox employed by architects and urban planners in representing the urban environment, that is mainly focused on providing visual outcomes, by introducing a reflection on the qualitative aspects of the sonic environment. The urban district of the Politecnico di Milano is used as testing ground of the technologies employed, specifically the game engine Unity and the online location-based service Google Earth ${ }^{1}$. The article firstly introduces the theoretical context in which the research is situated by presenting the terms of soundscape and soundwalk and providing a focus on the currently representation media used to describe the sonic environment; then the role of the virtual environments, as supports for providing further simulations, and not only as means for providing visual outcomes, will be approached; finally will be presented the outcomes obtained by the technologies employed and limits, potentialities and future applications will be highlighted.

2 In our everyday experiences, within the urban environment, we are continuously immersed into unique sensory compositions, that are integral parts of the identity of our cities. Their different structures depend on the properties of the building materials used, the different morphologies of the urban fabrics, the presence and peculiarities of the 
urban furniture and of the dynamic components, both natural and anthropogenic. By walking from a wide open space to a tree-lined avenue, we can perceive how the vegetation affects and reduces the diffusion of the traffic noise, or the peaceful sound produced by a breeze blows through the leaves. At the same time, we can perceive how the local climate changes, letting us feeling the coolness during a warm day, thanks to the effects of shadowing and the increases humidity. In addition, some of these trees can produce olfactory stimuli that can be perceived as pleasant or not, and contrasting with the others sensory experiences. It is the case of the Ginkgo Biloba a pleasant-looking tree that produces fruits that emanate a characteristic bad smell when they drop on the ground. We are constantly exposed to a superimposition of different sensory-scapes, characterized by blurred and fragmented boundaries changing over time, that are intertwined all together and are perceived simultaneously (Degen, 2008; Pallasmaa, 2005; Martellotti, 2004). However, an oculo-centrist approach has often driven the design of new urban public spaces, while the others sensory spheres have been mainly considered as pollutants that need to be reduced below a certain value, and confining the sensory complexity of the urban environment as a consequence of the design process rather than part of it. As argued by Mirko Zardini,

City planning has long privileged qualities of urban space based exclusively on visual perception. Above all, sounds and odours have been considered disturbing elements, and architecture and city planning have exclusively been concerned with marginalizing them, covering them up, or eliminating them altogether (Zardini, 2005, p. 20).

3 This situation is worsened by the current regulations that consider the sensory spheres from a quantitative point of view, providing thresholds and planning rules that have to be respected in order to avoid hazardous situations for city-users. Nevertheless, this reductionist approach provides just a partial description of the sensory form of the urban environment and it does not reveal the negative or positive effects that are provided by the various sensory stimuli (Kihlman, Kropp, Ohrstrom et al., 2001), therefore these approaches are not enough to ensure a complex and necessary description of the urban open spaces.

The most beautifully designed public square is destroyed if a noisy and odorous motorway is nearby, and not much would be left of the special atmosphere of the Piazza della Fontana di Trevi in Rome if the sound and coolness deriving from the running water was missing (Lucas \& Mair, 2008).

\section{Soundscape: a brief introduction to the theme}

Current regulations and common design practices considered the auditory stimuli in terms of noise that needs to be reduced, while their qualitative aspects are often taken into account only in design projects concerning acoustical purposes e.g. theaters, cinemas, concert halls, auditoriums (Raimbault \& Dubois, 2005). This is the case of the urban open spaces that are often treated as sources of disturbance (noise) towards indoor spaces, rather than places in which the qualitative aspects of the sonic environment should be valorized and preserved when they are good in order to ensure the physical and psychological wellbeing of the city-users. Various European research projects (e.g. Quadmap, Qside, Hush, Harmonica, Silence, CityHush, Hosanna ${ }^{2}$ ) and national researches (Grimwood 2011; Licitra, Chiari, Ascari et al., 2011; Payne, Davies \& Adams, 2009; Faburel \& Gourlot, 2008) demonstrated the limitations of quantitative noise control strategies and 
the need of multidisciplinary approaches to evaluate the qualitative and perceptual peculiarities of the urban sonic environment. They have also highlighted the importance of apply these approaches since the very beginning of the design process in order to conceive the sounds as resources rather than wastes (Kang, Chourmouziadou, Sakantamis et al., 2013).

5 The attention on the qualitative aspects of the sonic environment has a long history (McCartney, 2010; Radicchi, 2012); however, a significant step forward is given by the works conducted from the late sixties and the early seventies by the World Soundscape Project, a research group established by Murray Schafer at the Simon Fraser University in Vancouver (Schafer, 1977a). We owe to Schafer, and his research group, the establishment of a wide terminology, still used, that allows us to deal with the acoustic dimension of the urban environment. Schafer introduces the terms of acoustic ecology and soundscape (Schafer, 1977a), the latter derived from the term of landscape, which refers to "our sonic environment, [or] the ever-present array of noises with which we all live" (ibid., back cover), focused "on the way it is perceived by the individual, or by a society" (Truax, 1999). Schafer outlined the dominance of the visual modality in our society and negative effects of noise pollution in contemporary cities, and the needs on reestablishing attention on our everyday sounds through a series of exercises useful to re-accustom to a listening practice that we lost in our eye-culture society (McCartney, 2010; Wrightson, 2000; Schafer, 1977a; Schafer, 1992).

The Canadian research group provided methods for describe the aural components of soundscapes through three main analytical concepts (Truax, 1999):

- Keynote sounds, "sounds heard by a particular society continuously or frequently enough to form a background against which other sounds are perceived";

- Sound signals, "compared to noise which is unwanted sound, a signal is any sound or message which is meant to be listened to, measured or stored"

- And sound marks, "refer to a community sound which is unique, or possesses qualities which make it specially regarded or noticed by the people in that community. Soundmarks, therefore, are of cultural and historical significance and merit preservation and protection" ${ }^{5}$ ;

The analysis of their combinations and characteristics allow us to recognize lo-fi and hi-fi soundscape: the former refers to a sonic environment where the sound events are hard to extricate (like the soundscape that we can perceive in a crowded city); the latter describe an environment in which all the sound events are clearly understandable (Schafer, 1977a). Starting from the researches of the World Soundscape Project, various research groups have begun to inquire the qualitative aspects of the sonic environment and other classification methods and approaches have been consequently developed. Within the context of the urban design and planning, deserves to be mentioned laboratory CRESSON (Centre for research on sonic space and urban environment), established in the school of architecture of Grenoble in 1979 by Jean-François Augoyard. Through an interdisciplinary approach centered on architecture, urban planning, engineering acoustics, anthropology, sociology, and music composition, the CRESSON developed tools and methodologies able to provide a combined reading of the physical (quantitative) and perceptual (qualitative) characteristics of our sonic environment (Tixier \& Melemis, 2010; Amphoux, 2003; Thibaud, 2001; Augoyard, 1995). An effective tool developed by the CRESSON is the sound effect: according to Augoyard and Torgue, it is placed at an intermediate level between the sound object (Schaeffer, 1966), that is too detailed and disconnected from its actual 
source, and the soundscape (Schafer, 1977a), too general and broad to provide an accurate description of the sonic environment (Augoyard \& Torgue, 2003). The sound effect allows to describe the relation between the sound event, the built environment and the perception of the user in the urban space, and can be conceived not only as a classification method, but also as an actual tool able to enrich urban planning practices ( ibid.). Recently, the COST action named Soundscape of European Cities and Landscapes ${ }^{6}$ has published a report that collect the recent developments in soundscape studies into the realm of the urban and rural environment. Researchers from different disciplines provided guidelines, case studies and results on the effect of vegetation on the sonic environment, the methods of classification of the sound events and sound sources, the physical and psychological effects of the sound environment on the city-users, the description and analysis of the quiet areas, and in-depth analysis on new methodologies employed to analyze and describe the sound environment embracing both quantitative and qualitative approaches (Kang et al., 2013).

\section{An operational tool for investigate the sonic environment}

8 In order to investigate the perceptible aspects of the sonic environment an intimate survey approach of the urban public spaces is required (Gehl \& Svarre, 2013; Secchi, 1995; Porteous, 1990). An effective and straightforward method to analyze the sensory form of the urban environment and its temporality is to walk in it. By walking we can reveal the hidden palimpsest of the sensory stimuli, revealing their pace and precise localization, from a street-level view (Wunderlich, 2005). In soundscape studies the act of walking has been extensively employed as privileged survey tool. A first definition of this activity was provided by the World Soundscape Project during the sixties, that coined the term soundwalk (Paquette \& McCartney, 2012; Butler, 2006):

[...] any excursion whose main purpose is listening to the environment. It is exposing our ears to every sound around us no matter where we are. We may be at home, we may be walking across a downtown street, through a park, along the beach; we may be sitting in a doctor's office, in a hotel lobby, in a bank; we may be shopping in a supermarket, a department store, or a Chinese grocery store; we may be standing at the airport, the train station, the bus-stop. Wherever we go we will give our ears priority. (Westerkamp, 1974, p. 18)

9 In other terms the "Soundwalks take the everyday action of walking, and everyday sounds, and bring the attention of the audience to these often ignored events, practices and processes" (McCartney, 2010). During the last decades the soundwalk has been adapted and reinterpreted by various research groups for different purposes (ibid.): the soundwalk can take place in urban or rural areas; it can be performed individually (Jeon, Hong \& Lee, 2013) or in group (Drever, 2013). The soundwalk can be guided by an expert that defines several listening spots along the path or can be a continuous path that moves through the environment. A questionnaire or a interview can be performed during the soundwalk (Thibaud, 2001), or at the end of the experience as a form of reactivated listening. In this last case the user can experience the recorded soundscape, employing different sound equipments, in laboratory, detached from the real environment (Guastavino \& Katz, 2004; Augoyard, 2001). Moreover, a soundwalk does not have time or space constraints, could be performed for one hour or some minutes, it can be performed along a predefined path or can be performed in an area with undefined boundaries, 
where the listener decides his/her own path (suggested, sometime, by the sonic environment itself). Thus, the soundwalk can be used for achieving different aims: it can be use for analyze the sonic environment, but also to produce it (Mayer, 2007); It can be employed as a pre-recorded audio guide for touristic purposes, within the city, an archaeological site or inside a museum (McCartney, 2010). The soundwalk can be used for increasing the awareness of citizen on their sonic environment (Adams, Cox, Moore et al., 2006), as a pedagogical activity for students (Schafer, 1992) and as an operational tool for architects and urban planners (Tixier \& Melemis, 2010; Adams, Bruce, Davies et al., 2008; Venot \& Semidor, 2006). The above description is far to be exhaustive, but it shows the level of heterogeneity of this operational tool and therefore of the soundscape studies.

\section{Visualizing sounds}

10 As beforehand mentioned, in the urban practices the sonic environment is often treated in terms of noise and described using average and quantitative indices. A well known cartographic media used to represent the data collected concerning the noise, and required by recent regulations (END 2002/49/EC, 2002), is the noise map. Through graphical techniques (points, lines, areas) and color coding, a noise map can be use to represent the spatial and temporal distribution of the noise produced by various sources. Using these maps it is possible to display if the noise exceeds the limit values defined by the regulations; dwellings, schools and hospitals exposed to a certain value of a noise indicator; the number of people located in a specific area and the value of noise to which they are exposed (ibid.). The various auditory stimuli are reduced to aggregated numerical indexes, then translated into visual cues. It is evident that this approach leads to lose the peculiarities and the nuances of the sonic environment, not least the meaning that is incorporated into every sound event. In other words, these products provide just a partial and quantitative description of the sonic environment.

11 Cartographic media have been employed also as solutions for representing the qualitative aspects of the sonic environment. Thus far, the majority of the products developed in this direction have been named as soundmap or sound map, even though a formal definition as well as precise guidelines for their creation, in contrast to the noise maps, is still lacking. Briefly, a soundmap is a form of cartographic representation that permits to describe and localize the sonic components of a specific place. First examples of these means can be found from the research of Michael Southworth (1969) and in the works of the World Soundscape Project, specifically in the Five Village Soundscapes project (Schafer, 1977b). Subsequently, other examples have been developed such as in the urban design disciplines through the use of Geographic Information Systems (Balaÿ, 2004; Arlaud, 2001). However, the majority of these maps have been developed since the last two decades, with the growing concept of web 2.0 and in particular from 2005 when Google provided the Application Programming Interface (API) for their online location based service Google Maps. Through these technologies, digital maps have been enriched with the recorded sound fragments, precisely geolocated, using mash-up techniques ${ }^{7}$.

12 Various techniques can be employed for gathering the sound data: by using different methods and equipments for recording the sounds, such as binaural, stereo or soundfield microphones, from a fixed position or during a soundwalk, or by employing crowdsourcing data, means audio file directly created and uploaded by users using different devices such as mobile phones ${ }^{9}$. Moreover, soundmaps can be employed for 
representing specific sound sources ${ }^{10}$ or the entire complexity of the sonic environment ${ }^{11}$; they can be integrated with photographs or other multimedia objects ${ }^{12}$, and enriched with other information related to the sound recorded, like personal perceptions of the sound environment (Mydlarz, Drumm \& Cox, 2011) or the context of the research conducted. Finally, like the soundwalks, also the soundmaps can be developed for different purposes ranging from artistic products, memory archives or communication of research outcomes such as in the ethnography field ${ }^{13}$.

The research here presented aims at investigate, through interactive simulations and virtual environment, innovative methods to reenact the soundwalk experience by employing a multimodal representation that considers visual and auditory stimuli together (Ruotolo, Maffei, Di Gabriele et al., 2013; Viollon, Lavandier \& Drake, 2002; Southworth, 1969). Within this context, the use of three-dimensional virtual environments can reveal further solutions for the representation of the sonic environment within the urban practices, by providing an effective support that can overcome some limitations of the cartographic media presented. In fact:

- A map is two-dimensional and generally static, while the sonic environment occurs in a full three-dimensional space, characterized by blurred boundaries, and strongly related to different temporal spans;

- Cartographic media provide a partial and mono-sensory representation without taking into account the others sensory stimuli or the physical dimension of the urban fabric that interact with the sound environment;

- The technical jargon used and the graphic techniques employed in particular in noise maps, is difficult to comprehend for non-experts and this can generate misunderstanding (e.g. noise maps required by the European directive are focused on noise produced by transport infrastructures and do not consider other noise sources);

\section{3-D models as simulation background}

In the last decades, the use of three-dimensional models in urban studies has taken a step further: they have been employed not only for representing existing or designed urban public spaces, but as an effective background for further analysis. For instance, threedimensional models can be used for displaying the outcomes of different design scenarios to non-experts, avoiding a technical jargon, and giving the possibility to describe elements that can be just partially represented employing the traditional twodimensional media (Crooks, Hudson-Smith \& Patel, 2010; Milton, Anand, Batty et al., 2010; Cecconello \& Spallazzo, 2008; Evans, Hudson-Smith \& Batty, 2005; Bulmer, 2001; Batty, 2000). However, their use for the description of the sensory form of the urban environment is less investigated. Hence, how a method such as the soundwalk can be experienced and enriched through a virtual three-dimensional model?

The current three-dimensional modeling software are not suitable for creating simulation enriched by auditory components or to provide interactive solutions, therefore, new kinds of tools are needed to manage this sensory complexity and the data that we want to incorporate and communicate. Two different products were tested for this purpose, Google Earth ${ }^{14}$ and Unity ${ }^{0}{ }^{15}$. Google Earth is a well-known software, provided by Google, that allows the users to interactively visualize satellite images of the globe surface with a high level of details and with a user friendly and intuitive interface. During the last years this product has been enriched with various data such as textured three-dimensional 
models of several cities, included the vegetation, digital models of the terrain, various information layers such as historical maps, multimedia objects etc. Moreover, Google Earth is not just a passive tool: it allows the users to draw points, lines and areas on the maps, to insert three-dimensional models realized with various modeling software in order to enrich the base model provided (even if the complexity of the models imported, in terms of number of geometries, should be carefully evaluated in order to ensure an adequate fruition of the simulation); it allows to embed data obtained from GPS tracking or dataset employed in Geographic Information System; it is possible to include animated data, interactive interfaces and multimedia elements. Finally, the software has another useful tool that permits to create virtual tours along a predetermined path (Kim, Oh, Lee et al., 2011).

The other software considered in the research is the game engine Unity . A game engine is a software system designed for the creation and development of video games and characterized by various components: a render engine that provides the visualization of the three-dimendional models imported, an audio engine for the auralization of the virtual environment and various frameworks for manage animations and set up the artificial intelligence behaviors (Andreoli, De Chiara, Erra et al., 2005). In the last few years, a sort of pitch invasion of this technologies had been noticed, and this type of software is increasingly applied also in other fields not closely related to a playful attitude, such as the serious games. It is possible to find various examples of application of these software within the architectural field, and more precisely in the cultural heritage domains, where the game engine systems are used for developing virtual museum ${ }^{16}$, while their employment within the urban practices is less investigated (Bishop, 2011; Pauwels, Meyer \& Campenhout, 2010; Shamus \& Trenholme, 2009; Morgan, Gill, Lange et al., 2009; Indraprastha \& Shinozaki, 2009; Harvey \& Leong 2005; Herwing \& Paar, 2002). The high level of details reachable by these software, in terms of graphical representation, their flexibility and possibility to customize the final products through different programming languages, allow us to create highly interactive products where the users are not just spectators.

\section{Reenacting the soundwalk through virtual environments}

17 The two software were employed to reenact soundwalks recorded within the Politecnico di Milano, and along via Edoardo Bonardi (Illustration 1). The segment of street chosen separates the engineering school from the architecture school. It is 250 meters long and has a tram line in the center, that is flanked by two rows of trees, then two lanes for each direction of travel and two sidewalks. The university buildings have different heights and facade materials, and the urban fabric does not make up a continuous street canyon.

The aim was to create a detailed three-dimensional model of this area that permits to experience a street-level point of view. 
Illustration 1: Via Edoardo Bonardi, Milan, and the surroundings used in both devices

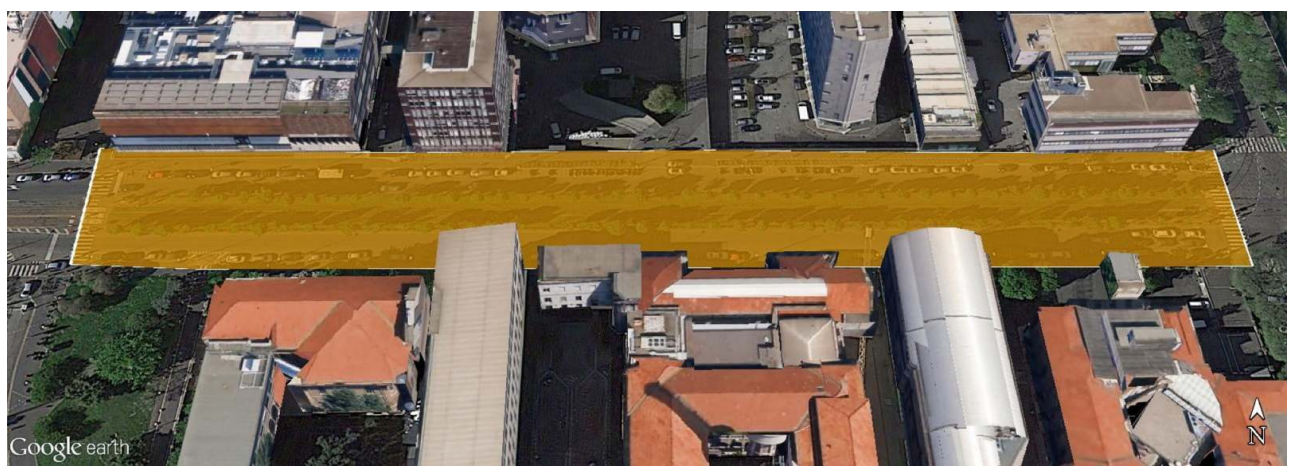

SOURCE AND COPYRIgHT: GOOgLE EARTH

19 For both software the first step was to gather the basic data for the creation of the virtual environment: the terrain, the street network, the buildings, the vegetation and the urban furniture, the dynamic components, such as traffic and pedestrian flows and finally the various sound events occurred during various days. Google Earth provides a three dimensional model of Milan. It has, however, a low level of detail for providing an effective street-level simulation at the neighborhood scale. The model has a low resolution digital elevation model of the terrain and the satellite images lack an adequate accuracy to a close distance; the three dimensional models of the buildings are simply extruded without any details aside the photorealistic textures applied on the facades. Moreover, the model lacks of the urban furniture and other details such as the fences, the street lighting and the rows of trees. Therefore, these elements have been modeled using 3D Studio Max (a three-dimensional modeler software) by employing the territorial data provided by the city of Milan, and in situ surveys, or readymade models, specifically for the urban furniture and other elements such as cars (Illustration 2).

Various soundwalks were performed in various hours of the day in order to identify the temporary and continuous sound sources that characterize the area. The soundwalks were recorded using a Roland R-05 digital audio recorder with the inbuilt stereo microphones and saved as a Wave 24bit file format at $48.0 \mathrm{kHz}$. The path followed, in terms of starting point, end point, direction and walking speed, was the same for all the recordings. These elements were collected and employed as input data to develop the soundwalk in the virtual environment. The digital recorder was facing the path, parallel to the ground, at 1.5 meters height. Through this method it was possible to collect also the sound events not directly visible and located in the surroundings of the chosen street (within the limits of the equipment used). Besides the soundwalks in the same days were individually recorded also other sound sources in order to provide a collection of audio samples to be used in the virtual environment. All the sound sources were recorded as close as possible in order to reduce the interference provided by the environmental noise. The same recording device and the same setup was used in these surveys. This procedure provides an approximate recording of the sound source, that is sufficient for our aims. Another possibility, more complex and not always applicable, is to reproduce only a specific sound source in a controlled environment such as an anechoic chamber (Galbrun \& Ali, 2012). All the recordings were analyzed and divided into categories: there are linear sources, such as the tram or the vehicular traffic flow, point sources as the air conditioning systems or the buzzer of the barrier when entering the parking lot, and 
others sound sources located far from the path chosen, but still audible, such as the church bells and the sirens of ambulances and police's cars.

In the first simulation a virtual tour, based on data collected during the survey (length, position and direction of the path), has been generated using the inbuilt tool of Google Earth. The height of the camera and the point of view were also defined. Then, the soundwalk recordings have been added. This is a task that cannot be implemented directly within the software environment. The tour created has to be exported in Keyhole Markup Language (KML) file format then, using a text editor, it is possible to modify the tour by adding the information needed for playing the sounds. Once the KML file has been modified, and the audio file connected, it is possible to display the simulation in Google Earth (Video 1).

This media file cannot be displayed. Please refer to the online document http:// journals.openedition.org/ambiances/657

Illustration 2: From the left: the real environment compared with the low resolution 3-D model provided by Google Earth and the 3-D model enriched by the Author

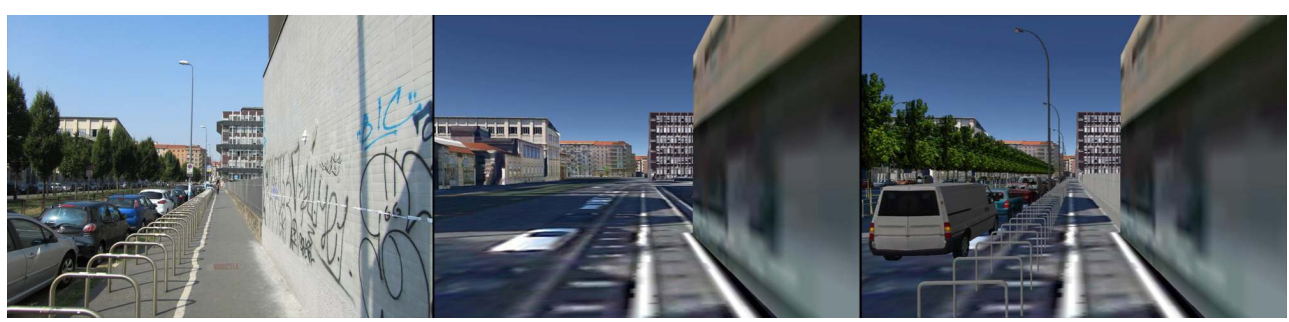

SOURCE: GOOgLE EARTH AND AUTHOR. COPYRIgHT: GOOgLE EARTH, IMAgE LANDSAT IMAgE 2014 DigitALgLOBE

Due to the lack of the dynamic elements in this first simulation, such as the vehicular traffic flow and the pedestrians, the correspondence between sound events and their sources is missed. This aspect can be misleading for the users. Moreover, the interactivity of the products is limited, only the recorded path can be shown and the user is blocked on a predesigned track without the possibility to turn his/her head. Another limit of the product regards the virtual environment itself: while the 3-D model can be easily enriched, the aerial base map cannot be modified. Moreover, Google Earth provides well textured models only for the buildings next to the street network while the buildings facing the enclosed spaces do not have the same level of detail. However, considering the difficulty needed for modeling a complex urban environment, a readymade model permits to substantially reduce the time employed for setting up the simulation.

The second device was developed using the game engine system Unity. As explained above game engines allow us to develop products in which the users can freely interact with the virtual environment, without constraint if not imposed by the designer. The drawback is that the virtual model has to be entirely prepared, taking into account the difficulty to find the data as described beforehand. The sound components can be individually spatialize allowing us to reproduce the sonic environment in a more complex manner; however, this task can be hardly achieved due to the fact that some sound sources, even if perfectly audible, are located far from the place considered and therefore difficult to record and to edit (such as the church bells, the siren of an ambulance or an airplane passing overhead). As the product previously developed, the first step regards 
the creation of the three-dimensional model. Thanks to the flexibility of the game engine it was possible to use, with minor adjustment, a readymade model developed and employed at the Laboratorio di Simulazione Urbana "Fausto Curti".

The virtual model was imported into the game engine environment then, using the builtin programming tools, also the dynamic components of the traffic, the tram, and the pedestrian flow have been added. The animations follow simple behavioral rules (such as the obstacle avoidance rules), means that complex artificial intelligence behaviors have not been implemented. In order to recreate a closer urban experience of the soundwalk, and not only focus the attention on the sound components, have been taken into account also the visual stimuli, a directional light simulating the sun, and the corresponding shadows, were created. Through programming code and a graphical user interface the position of the light can be modified in real time according to the position of the sun during the solstices and equinoxes for three different hours of the day (Illustration 3). Finally, the virtual environment were enriched with the sounds recorded in situ connected to the location of their virtual source. Compared to the previous method, the interactivity of the final product is improved thanks to the possibility to properly localize the sound elements into the virtual environment. That allows the user to experience different paths and sonic scenarios also by activating and deactivating individually the various sound sources.

In this first version of the device it was used the sound engine FMOD built-in the game engine system. This component permits to perform an accurate spatialization of the sound sources and to take into account the acoustic attenuation due to the distance. It is possible to add different sound filters to enrich the details of the sonic environment, such as the Doppler effect for simulating the changing of frequencies of a moving sound source (for example a siren or a cars), or a filter for modifying the reverberation time of the virtual space, in order to simulate different materials and physical configurations of the environment. However, some limitations still remain. It is not possible to take into account two important aspects like the partial or total sound occlusion effect, that occurs when the sound wave is hindered by an object located between the sound source and the listener; and the reflections of the sound waves according the different materials. Both can be resolved by using different expedients, but we cannot consider this simulation as physically correct (Video 2).

This media file cannot be displayed. Please refer to the online document http:// journals.openedition.org/ambiances/657 
Illustration 3: The 3-D model of via Edoardo Bonardi and surroundings, imported into the game engine environment

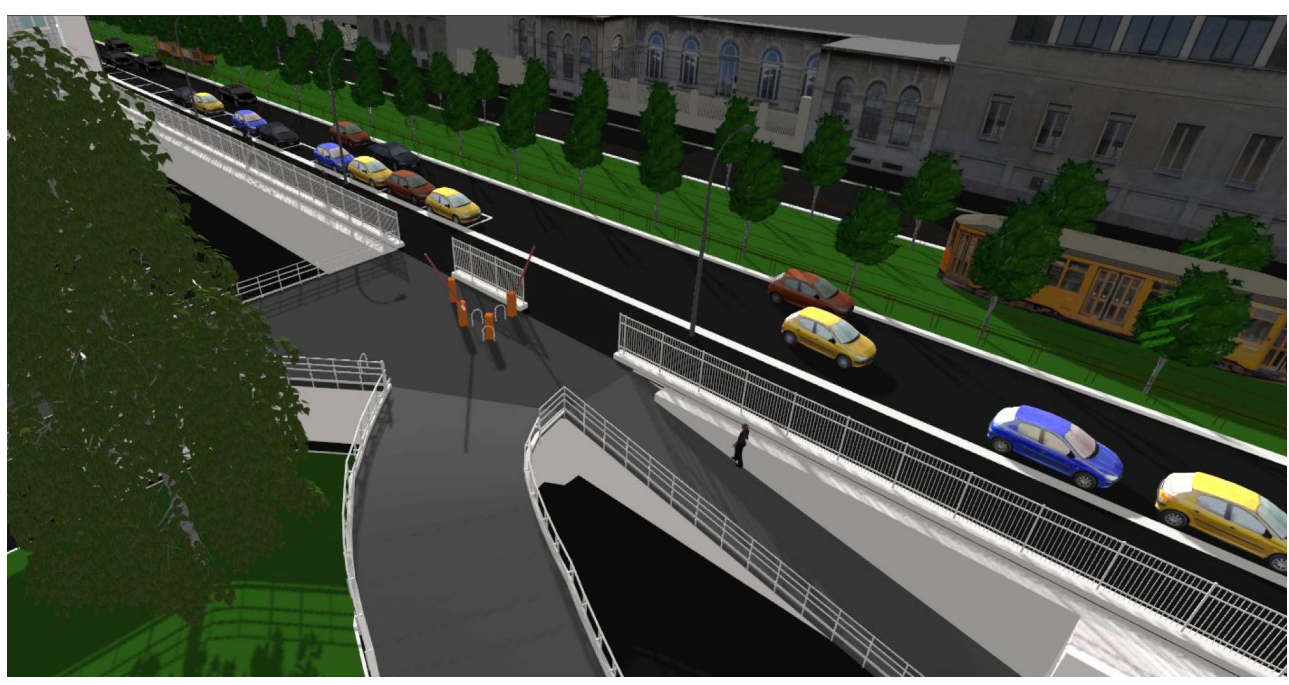

SOURCE AND COPYRIgHT: AUTHOR

\section{Conclusion and future works}

The research aimed to provide an insight on tools able to enrich the representation of the urban environment through auditory components and interactive solutions. Over the last few years, the use of three-dimensional urban models has substantially grown thanks to the improvements of information technologies. However, the usefulness provided by these supports is generally underestimated and their usage is often focused to obtain visual representations for communication and marketing purposes and, in the majority of the cases, at the end of the urban design process. Within the research, the threedimensional model is conceived, since the beginning of the urban design process, as a means for further analysis and as a media capable of linking the visual perception to the sonic experience through a multimodal representation, wherein interactivity, temporality and dynamic components of the urban environment are also considered.

Rather than developing a product from scratch, the aim of the research was to investigate and test the effectiveness of existing tools, even if not belonging to the field of urban studies (Google Earth and Unity), in reproducing the experience of the urban sensory environment. Between them, the game engine technologies are effective solutions to achieve this purpose, thanks to the ability of handling complex three-dimensional models within an interactive, customizable and flexible virtual environment, and to integrate and manage multiple sonic data. The developed device can be employed to present, in real time, different complex scenarios that can be easily communicated, evaluated and manipulated by expert and lay people involved in the various phases of the urban planning process.

The ongoing research has highlighted different aspects that need to be further investigated. A first hindrance regards the development of the three-dimensional models that, nowadays, remains the most time-consuming task, due to the limited access to high resolution data and the level of detail needed for providing an effective simulation at the street-level. Rapid modeling techniques, such as three-dimensional photogrammetric, as 
well as the growing availability of urban models in open data format, are promising solutions that can be likely be employed for reducing the time employed for the development of these inputs. A second limit is related to the accuracy of the created sonic environment from a physical point of view: due to the high number of heterogeneous variables, the calculation of reflections and diffractions of the sound waves in the urban fabric is still a difficult task to achieve. Beyond the limits of the visual and auditory simulation, an important aspect that needs to be considered regards the devices and interfaces used by the users for displaying and controlling the simulation itself.

In the last few years the game industry has developed innovative and affordable virtual reality devices that can be tested in order to evaluate their effectiveness compared to the current control system, based on mouse and keyboard. A further step in the research will be to perform an in-depth analysis on the users' response on these products (an aspect that was not treated in the research so far), taking into account the devices used for the experience (visual and auditory systems and controlling devices).

To conclude, the possibilities given by game engine technologies allow us to provide effective means for expand the toolbox used within the urban design process. They can be employed as useful devices to extend the potentialities of the three-dimensional models, in order to consider them as background for further analysis and for establishing new form of dialogue with city-dwellers. Lastly, the results of this research prove that these technologies, although belonging to disciplines not directly linked to the urban practices, can be effectively used for envisioning new trails in the research field of the sensory perception in the urban environment, by providing innovative means for obtaining multimodal and immersive representations.

\section{BIBLIOGRAPHY}

\section{Bibliography}

Adams, Mags; Cox, Trevor; Moore, Gemma; Croxford, Ben; Refaee, Mohamed \& Sharples, Steve. 2006. Sustainable soundscapes: noise policy and the urban experience. Urban Studies, vol 43, $n^{\circ} 13$. p. 2385-2398.

Adams, Mags; Bruce, Neil; Davies, William; Cain, Rebecca; Jennings, Paul; Carlyle, Angus; Cusack, Peter; Hume, Ken \& Plack, Christoper. J. 2008. Soundwalking as a methodology for understanding soundscapes. In: Institute of Acoustics, Spring Conference, Widening Horizons in Acoustics. 10-11 April 2008. Volume 30 part 2. Reading, United Kingdom: Institute of Acoustics.

Amphoux, Pascal. 2003. Ambiance architecturale et urbaine. In: Lévy, Jacques \& Lussault, Michel (eds.). Dictionnaire de la géographie. Paris: Belin. p. 60-61.

Andreoli, Roberto; De Chiara, Rosario; Erra, Ugo \& Scarano, Vittorio. 2005. Interactive 3D Environments by Using Videogame Engines. In: Ninth International Conference on Information Visualisation (IV'05). London: IEEE Computer Society. p. 515-520. 
Arlaud, Blaise. 2001. Vers une infographie de l'ambiance sonore urbaine [online]. PhD thesis. Nantes, Grenoble: Université de Nantes, Ecole d'Architecture de Grenoble, CRESSON UMR 1563. Available online at: http://tel.archives-ouvertes.fr/tel-00448702 (consulted on May 20, 2014).

Augoyard, Jean-François. 1995. L'environnement sensible et les ambiances architecturales. Espace géographique, vol 24, $n^{\circ}$ 4. p. 302-318.

Augoyard, Jean-François. 2001. L'entretien sur écoute réactivée. In: Grosjean, Michèle \& Thibaud, Jean-Paul (eds.). L'espace urbain en méthodes. Marseille: Editions Parenthèses. p. 127-153.

Augoyard, Jean Francois \& Torgue, Henry. 2003 [1995]. Repertorio degli effetti sonori. Lucca: Libreria Musicale Italiana.

Balaÿ, Olivier. 2004. Discrete mapping of urban soundscapes. Soundscape - The Journal of Acoustic Ecology, vol 5, n 1. p. 13-14.

Batty, Michael. 2000. The new urban geography of the third dimension. Environment and Planning B: Planning and Design, vol 27, $\mathrm{n}^{\circ}$ 4. p. 483-484.

Bishop, D. Ian. 2011. Landscape planning is not a game : Should it be?. Landscape and Urban Planning, vol 100, n 4. p. 390-392.

Bulmer, Daniel. 2001. How can computer simulated visualizations of the built environment facilitate better public participation in the planning process [online]. Online Planning Journal. Available online at: http://www.casa.ucl.ac.uk/planning/articles61/complanning.pdf (consulted on May 20, 2014).

Butler, Toby. 2006. A walk of art: the potential of the sound walk as practice in cultural geography. Social \& Cultural Geography, vol 7, n 6. p. 889-908.

Cecconello, Mauro \& Spallazzo, Davide. 2008. Virtual Reality for Enhanced Urban Design. In: Proceedings of 5th INTUITION, International Conference Virtual Reality in Industry and Society: From Research to Application. 6-8 Ottobre 2008. Torino.

Crooks, Andrew; Hudson-Smith, Andrew \& Patel, Amit. 2010. Building 3D agent-based models for urban systems [online]. CASA Working Papers Series 161 (November 2010). London: Center of Advanced Spatial Analysis, University College London. Available online at: https:// www.bartlett.ucl.ac.uk/casa/pdf/paper161.pdf (consulted on May 20, 2014).

Degen, Mònica Montserrat. 2008. Sensing Cities. Regenerating public life in Barcelona and Manchester. New York, NY: Routledge.

Drever, John L. 2013. Silent Soundwalking: an urban pedestrian soundscape methodology. In: AIADAGA 2013, the joint Conference on Acoustics, European Acoustics Association Euroregio, 39th annual congress of the Deutsche Gesellschaft für Akustik and the 40th annual congress of the Associazione Italiana di Acustica. Merano, Italy: Goldsmiths Research Online.

END 2002/49/EC. 2002. Directive of the European Parliament and of the Council of 25 June 2002 relating to the assessment and management of environmental noise. Environmental Noise Directive. Official Journal of the European Union, L189 18 July 2002. p. 12-26.

Evans, Steve; Hudson-Smith, Andrew \& Batty, Michael. 2005. 3-D GIS : Virtual London and beyond [online]. Cybergeo: European Journal of Geography, Dossiers, Sélection des meilleurs articles de SAGEO 2005, document 359. Available online at: http://cybergeo.revues.org/2871 (consulted on May 20, 2014).

Faburel, Guillaume \& Gourlot, Nathalie. 2008. Référentiel national pour la définition et la création des zones calmes [online]. Available online at: http://www.developpement-durable.gouv.fr/IMG/pdf/ 
Referentiel_national_pour_la_definition_et_la_creation_des_zones_calmes_-_2008-2.pdf

(consulted on June 20,2014).

Galbrun, Laurent \& Ali, T. Tahrir. 2012. Perceptual assessment of water sounds for road traffic noise masking. In: Proceedings of the Acoustics 2012 Nantes Conference, 23-27 April. Nantes, France. p. 2153-2158.

Gehl, Jan \& Svarre, Birgitte. 2013. How to study public life: methods in urban design. Washington D.C.: Island Press.

Grimwood, Colin. 2011. Soundscape, Quiet Areas \& Health. A national and local challenge. In: COST TD0804: Soundscape of European Cities and Landscapes, Workshop on General policy Approaches in Soundscape Implementation, 6-7 April 2011, Brighton.

Guastavino, Catherine \& Katz, F. G. Brian. 2004. Perceptual evaluation of multi-dimensional spatial audio reproduction. The Journal of the Acoustical Society of America, vol 116, $\mathrm{n}^{\circ} 2 . \mathrm{p}$. 1105-1115.

Harvey, Lawrence \& Leong, Kim. 2005. CitySounds, Community Sound Survey. Melbourne: RMIT University, SIAL Sound Studios. Research Report for the City of Melbourne Noise Unit.

Herwig, Adrian \& Paar, Philip. 2002. Game engines: tools for landscape visualization and planning. In: Buhmann, Erich; Nothelfer, Ursula \& Pietsch, Matthias (eds.). Trends in GIS and Virtualization in Environmental Planning and Design: Proceedings at Anhalt University of Applied Sciences .Wichmann Verlag: Heidelberg. p. 161-172.

Indraprastha, Aswin \& Shinozaki, Michihiko. 2009. The Investigation on Using Unity3D Game Engine in Urban Design Study. Communication Technology, vol 3, n 1. p. 1-18.

Jeon, Jin Y; Hong, Joo Y \& Lee, Pyoung J. 2013. Soundwalk approach to identify urban soundscapes individually. Journal of the Acoustical Society of America, vol 134, $\mathrm{n}^{\circ} 1$. p. 803-12.

Kang, Jian; Chourmouziadou, Kalliopi; Sakantamis, Kostantinos; Wang, Bo \& Hao, Yiying (eds.). 2013. Soundscape of European Cities and Landscapes [online]. Research Report COST TUD Action TD0804. Oxford: Soundscape-COST. Available online at: http://soundscape-cost.org/documents/ COST_TD0804_E-book_2013.pdf (consulted on June 20, 2014).

Kihlman, Tor; Kropp, Wolfgang; Ohrstrom, Evy \& Berglund, Birgitta. 2001. Soundscape support to health - a cross-disciplinary research program. In: Rinus, Boone (ed.), Inter-Noise 2001, proceedings of the 2001 International Congress and Exhibition on Noise Control Engineering, The Hague, The Netherlands, 27-30 August 2001. Maastricht: Nederlands Akoestisch Genootschap. p. 1237-1242.

Kim, Kihwan; Oh, Sangmin; Lee, Jeonggyu \& Essa, Irfan. 2011. Augmenting aerial earth maps with dynamic information from videos. Virtual Reality, vol $15 \mathrm{n}^{\circ} 2-3$. p. 185-200.

Licitra, Gaetano; Chiari, Claudia; Ascari, Elena \& Palazzuoli, Diego. 2011. Quiet area definition in the implementation of European directive 2002/49/EC. New Zealand Acoustics, vol 24, $\mathrm{n}^{\circ} 4$. $\mathrm{p}$. 20-26.

Lucas, Ray \& Mair, Gordon (eds.). 2008. Sensory Urbanism Proceedings 2008 (call for contribution). Glasgow, University of Strathclyde: The Flâneur Press.

Martellotti, Daniela. 2004. Architettura dei sensi. Roma: Mancosu Editore.

Mayer, Christoph. 2007. Audioweng Gusen [online]. Available online at: http:// www.audioweg.gusen.org (consulted on June 20, 2014).

McCartney, Andra. 2010. Soundwalking: creating moving environmental sound narratives. Soundwalking Interactions [online]. Available online at: http:// 
soundwalkinginteractions.wordpress.com/2010/09/27/\%20soundwalking-creating-movingenvironmental-sound-narratives (consulted on July 25, 2014).

Milton, Richard; Anand, Suchith; Batty, Michael; Crooks, Andrew; Hudson-Smith, Andrew; Jackson, Mike \& Morley, Jeremy. 2010. Data mash-ups and the future of mapping. United Kingdom: JISC. Research report JISC Techwatch Horizon Scanning.

Morgan, Ed; Gill, Lewis; Lange, Eckart \& Romano, Daniela. 2009. Rapid prototyping of urban river corridors using 3D interactive, real-time graphics. In: Buhmann, Erich; Kieferle, Joachin; Pietsch, Matthias \& Kretzler, Einar (eds.). 10th Conference on IT in Landscape Architecture. Malta: Anhalt University of Applied Sciences. p. 198-205.

Mydlarz, Charlie; Drumm, Ian \& Cox, Trevor. 2011. Application of novel techniques for the investigation of human relationships with soundscapes. In: INTER-NOISE and NOISE-CON Congress and Conference Proceedings, Volume 2011. Osaka, Japan: Institute of Noise Control Engineering. p. 738-744.

Pallasmaa, Juhani. 2005 [1996]. Gli occhi della pelle. L'architettura e i sensi. Milano: Editoriale Jaca. Paquette, David \& McCartney, Andra. 2012. Soundwalking and the Bodily Exploration of Places. Canadian Journal of Communication, vol 37, $\mathrm{n}^{\circ} 1$ [online]. p. 135-145. Available online at: http:// www.cjc-online.ca/index.php/journal/article/view/2543/2286 (consulted on June 20, 2014).

Pauwels, Pieter; Meyer, Ronald De \& Campenhout, Jan Van. 2010. Visualisation of semantic architectural information within a game engine environment. In: Makanae, Koji; Yabuki, Nobuyoshi \& Kashiyama, Kazuo (eds). 10th International Conference on Costruction Applications of Virtual Reality CONVR2010. Sendai: CONVR2010. p. 219-228.

Payne, R. Sarah; Davies, J. William \& Adams, D. Mags. 2009. Research into the practical and policy applications of soundscape concepts and techniques in urban areas (NANR 200). Salford: University of Salford. Research Report for the Department for Environment, Food and Rural Affairs, London. Available online at: http://randd.defra.gov.uk/Document.aspx?Document=NO0217_ 8424_FRP.pdf (consulted on June 20, 2014).

Porteous, J. Douglas. 1990. Landscapes of the mind: worlds of sense and metaphor. Toronto: University of Toronto Press.

Radicchi, Antonella. 2012. Sull'immagine sonora della città. Firenze: Firenze University Press. Raimbault, Manon \& Dubois, Danièle. 2005. Urban soundscapes: Experiences and knowledge. Cities, vol 22, $\mathrm{n}^{\circ}$ 5. p. 339-350.

Ruotolo, Francesco; Maffei, Luigi; Di Gabriele, Maria; Iachini, Tina; Masullo, Massimiliano; Ruggiero, Gennaro \& Senese, P. Vincenzo. 2013. Immersive virtual reality and environmental noise assessment: An innovative audio-visual approach. Environmental Impact Assessment Review, vol $41, n^{\circ} 1$. p. 10-20.

Schaeffer, Pierre. 1966. Le traité des objets musicaux. Paris: Ed du Seuil.

Schafer, R. Murray. 1977a. The tuning of the world. Toronto: Random House Inc.

Schafer, R. Murray. 1977b. Five Village Soundscapes, No.4, The Music of the Environment Series. Vancouver: A.R.C. Pubblication.

Schafer, R. Murray. 1992. A Sound Education: 100 exercises in listening and sound-making. Indiana River, Ontario, Canada: Arcana Editions.

Secchi, Bernardo. 1995. Dell'utilità di descrivere ciò che si vede, si tocca, si ascolta. II Convegno internazionale di Urbanistica, Prato, 30 marzo - 1 aprile 1995 (unpublished report). 
Shamus, P. Smith \& Trenholme, David. 2009. Rapid prototyping a virtual fire drill environment using computer game technology. Fire Safety Journal, vol 44, n 4. p. 559-569.

Southworth, Michael. 1969. The sonic environment of cities. Environment and Behavior, vol 1, $\mathrm{n}^{\circ} 1$. p. 49-70.

Thibaud, Jean-Paul. 2001. La méthodologie des parcours commentés. In: Grosjean, Michèle \& Thibaud, Jean-Paul (eds.). L'espace urbain en méthodes. Marseille: Parenthèses. p. 79-100.

Tixier, Nicolas \& Melemis, Steven. 2010. Urban transects. In: Klein, M. Rena; Hayes, L. Richard \& Ebbert, Virginia (eds.). 2010. Proceedings of ARCC/EAAE 2010 International Conference on Architectural Research, 23-26 June. Washington DC: Architectural Research Centers Consortium (ARCC). p. 219-226.

Truax, Barry (Ed.). 1999 [1978]. Handbook for acoustic ecology [online]. Available online at: http:// www.sfu.ca/sonic-studio/handbook (consulted on June, 20 2014).

Venot, Flora \& Sémidor, Catherine. 2006. The soundwalk as an operational component for urban design. In: Proceedings of PLEA 2006-The 23rd Conference on Passive and Low Energy Architecture, Genève 6-8 September 2006.

Viollon, Stephanie; Lavandier, Catherine \& Drake, Carolyn. 2002. Influence of visual setting on sound ratings in an urban environment. Applied Acoustics, vol 63, n 5. p. 493-511.

Westerkamp, Hildegard. 1974. Soundwalking. Sound Heritage, vol 3, n 4. p. 18-27.

Wrightson, Kendall. 2000. An introduction to acoustic ecology. Soundscape - The Journal of Acoustic Ecology, vol 1, $\mathrm{n}^{\circ} 1$. p. 10-13.

Wunderlich, F. Matos. 2005. Walking and rhythmicity: sensing urban space. In: The 6 th International Conference on Walking in the 21st Century, 22-23 September 2005, Zurich, Switzerland. Available online at: http://walk21.com/papers/Zurich\%2005\%20Matos\%20Walking\%20and\% 20rhythmicity\%20sensing\%20urban\%20space.pdf (consulted on May 20, 2014)

Zardini, Mirko. 2005. Toward a Sensorial Urbanism. In: Zardini, Mirko (ed.) Sense of the City: An Alternate Approach to Urbanism. Montreal: Canadian Center for Architecture.

\section{NOTES}

1. Google Earth is a trademark of Google, Inc.; Unity is a trademark of Unity Technologies.

2. http://www.quadmap.eu; http://www.qside.eu; http://www.hush-project.eu; http:// www.harmonica-project.eu; http://www.silence-ip.org; http://www.cityhush.eu; http:// www.greener-cities.eu (accessed January 2015).

3. http://www.sfu.ca/sonic-studio/handbook/Keynote.html (accessed January 2015).

4. http://www.sfu.ca/sonic-studio/handbook/Sound_Signal.html (accessed January 2015).

5. http://www.sfu.ca/sonic-studio/handbook/Soundmark.html (accessed January 2015).

6. http://soundscape-cost.org (accessed January 2015).

7. "The term mash-up refers to websites that weave data from different sources into new Web services" (Milton, Anand, Batty et al., 2010, p.1).

8. http://torontosoundmap.com; http://www.montrealsoundmap.com; http:// www.lisbonsoundmap.org (accessed January 2015).

9. http://www.firenzesoundmap.org; http://favouritesounds.org; http:// www.opensoundneworleans.com (accessed January 2015). 
10. http://www.soundsurvey.org.uk/index.php/survey/waterways; http://www.xeno-canto.org/ explore/region; http://sounds.bl.uk (accessed January 2015).

11. http://www.soundsurvey.org.uk/index.php/survey/soundmaps (accessed January 2015).

12. http://www.soundaroundyou.com (accessed January 2015).

13. http://www.alexandria-streets-project.net; http://map.europeanacousticheritage.eu; http:// www.cartophonies.fr (accessed January 2015).

14. http://earth.google.com

15. https://unity3d.com

16. http://www.v-must.net/virtual-museums (accessed January 2015).

\section{ABSTRACTS}

The purpose of this research is to develop a tool able to enhance the visual representation of urban environments through the auditory stimuli and dynamic components. Since the sixties, various qualitative studies have been conducted in order to reveal the role of the sonic environment in defining the physical and psychological wellbeing of the city-dwellers. Nevertheless, in urban planning practices and current regulations the sonic environment is often considered in term of pollutant (noise pollution) that need to be treated by applying quantitative approaches such as noise control strategies. The cause of this contradiction can be attributed, among other factors, by the lack of tools able to qualitatively describe the urban ambiances. The innovative technologies tested in this research, such as online location-based services and game engine systems, were used to develop devices able to provide a temporal and multimodal representation of the city. These devices explore the transposition, in a virtual environment, of the soundwalk conceived as an efficient technique for analyzing the sensible forms of the urban environment. The test of these digital tools allowed us to highlight limits and potentialities of the technologies employed.

L'objectif de cette recherche est de développer un dispositif numérique permettant de représenter les environnements urbains à travers leurs composantes sonores et dynamiques. Depuis la fin des années soixante, de nombreuses études qualitatives ont permis de révéler la diversité des effets de l'environnement sonore sur le bien-être physique et psychologique ressenti par les usagers. Pourtant, la prise en compte du sonore dans les documents de planification et d'urbanisme réglementaire s'établit principalement à partir d'études quantitatives qui réduisent le plus souvent le sonore à une pollution qu'il s'agit de réguler par l'imposition de normes. Ce constat s'explique notamment par l'insuffisance d'outils numériques permettant de décrire qualitativement les ambiances urbaines. Les technologies numériques innovantes expérimentées au cours de cette recherche, telles que les outils de géolocalisation en ligne et les systèmes de moteurs de jeux, ont permis d'élaborer des dispositifs de représentation temporelle et multimodale de la ville. Ce dispositif explore une transposition de la méthode du parcours sonore dans un environnement urbain virtuel. La mise à l'épreuve de ces outils numériques a également permis d'analyser leurs limites et d'envisager leurs potentialités. 
INDEX

Mots-clés: urbanisme sensoriel, paysage sonore, ambiances virtuelles, moteur de jeu, parcours sonore

Keywords: sensory urbanism, soundscape, virtual ambiances, game engine, soundwalk 